\title{
Be social! The impact of self-presentation on peer-to-peer accommodation revenue
}

Marta Nieto García ${ }^{\mathrm{a}}$, Pablo A. Muñoz Gallego ${ }^{\mathrm{b}}$, Giampaolo Viglia ${ }^{\mathrm{c}}$, Óscar Gonzalez Benito $^{\mathrm{d}}$

Keywords: self-presentation; social distance; latent topic modeling; revenues; Airbnb

${ }^{\text {a }}$ University of Portsmouth, Department of Marketing, Richmond Building, PO13DE Portsmouth, United Kingdom.

Corresponding author: marta.garcia@ port.ac.uk

${ }^{\mathrm{b}}$ Universidad de Salamanca, Departmento de Administración y Economía de la Empresa, Edificio FES Campus Unamuno, 37007 Salamanca, Spain. Telf. +34 923294500 (3127) pmunoz@usal.es

${ }^{c}$ University of Portsmouth, Department of Marketing, Richmond Building, PO13DE Portsmouth, United Kingdom.

giampaolo.viglia@port.ac.uk

${ }^{d}$ Universidad de Salamanca, Departmento de Administración y Economía de la Empresa, Edificio FES Campus Unamuno, 37007 Salamanca, Spain. Telf. +34 923294500 (3008) oscargb@usal.es 


\section{Abstract}

Online peer-to-peer platforms empower individual users and facilitate value-oriented exchanges. Personal profiles are the main point of contact with consumers on these platforms. Although individual sellers can use these profiles to market their own products, the optimal communication strategies that maximize their revenues remain uncertain. In line with construal-level theory, a self-presentation strategy that reduces social distance might increase sellers' revenues. An empirical validation, based on 6,074 Airbnb listings, affirms that self-presentation that evokes social values leads to higher revenues. The length of the self-presentation also exerts a notable impact. Specifically, an inverted U-shaped effect on revenues reaches its peak at 424 words. This research has rich managerial implications, in that it demonstrates how sellers on peer-to-peer platforms can increase their revenues simply by emphasizing social values in their selfpresentations.

Keywords: self-presentation; social distance; revenue; peer-to-peer accommodation; Airbnb; sharing economy 


\section{Introduction}

The so-called sharing economy offers an appealing alternative to traditional businesses, such that recent predictions anticipate more users and transaction values of around $€ 570$ billion annually by 2025 (Pricewaterhouse Coopers 2016). This growth largely stems from the development of social network platforms, which have fostered the creation and maintenance of online peer-to-peer marketplaces (Botsman and Rogers 2011; Tussyadiah and Pesonen 2016). These marketplaces enable individual users to share various goods and services; instead of buying and owning things, consumers access them temporarily (Bardhi and Eckhardt 2012). Peer-to-peer transactions have completely reshaped the travel and hospitality industry in particular, and platforms like Airbnb and Homestay allow individual sellers to market their own products (Botsman 2014; Cheng 2016; Dolnicar 2017; Karlsson and Dolnicar 2016; Sigala 2017).

To facilitate these transactions, and thus maximize the revenues they earn, sellers must determine how best to present themselves in these marketplaces (Caldieraro et al. 2018). Such questions have received scant research attention. We draw on construal-level theory (CLT; Trope and Liberman 2003) to investigate self-promotion in peer-to-peer trading and particularly how self-presentation strategies affect sellers' revenues. This theory offers a sound theoretical grounding for explaining consumers' elaboration of distant objects, such as accommodations, which inherently reflect some social distance from the host. We focus on self-presentation, because it affects perceived trustworthiness and booking intentions (Tussyadiah and Park 2018). With informative self-presentations, hosts can provide a more concrete construal of the distant outcome (i.e. the accommodation), which in turn might affect revenues (Forman, Ghose, and Wiesenfeld 2008; Larrimore et al. 2011). 
Such self-presentations often signal specific social values, which drive peer-to-peer transactions (Tussyadiah and Pesonen 2016) and motivate sellers to participate in the markets (Lutz and Newlands 2018). Social values can serve as "mottos" for peer-to-peer platforms (Gebbia 2016), yet sellers' final goal remains earning revenue (Abrate and Viglia 2019). Therefore, this study investigates whether a social-oriented selfpresentation strategy enables sellers to achieve this goal and maximize their revenues. In so doing, we make three main contributions to extant literature. First, this study advances recent research into the effectiveness of self-presentations. Tussyadiah and Park (2018) note the usefulness of self-presentations for trust building; we instead consider the effect of different self-presentation strategies on revenues. The findings suggest that self-presentation content influences sellers' revenues, such that, after controlling for other factors, listings that provide details about the social aspects of the experience lead to greater revenues. A self-presentation focused on sellers' personal interests instead has a negative impact on revenues. Second, drawing on decisionmaking theory, we tackle questions surrounding information disclosure and its effect on sellers' revenues; when sellers disclose too much information, it has a detrimental effect. Third, leveraging the social dimension of CLT (Trope and Liberman 2003), we demonstrate that social distance is a powerful tool for achieving revenue maximization. In the next section, we present the theoretical underpinning for this study in more detail. After we describe the methodological approach and derive the empirical analysis, we present the study findings and discuss them. Finally, we note some theoretical and practical implications, along with some limitations and areas for further research.

2. Social distance in the sharing economy 
Substantial research investigates the sharing economy from multiple perspectives, including its impacts on the accommodation sector (Guttentag 2015; Zervas, Proserpio, and Byers 2017), the risk of digital discrimination (Edelman, Luca, and Svirsky 2017), regulation issues (Koopman, Mitchell, and Thierer 2015; Williams and Horodnic 2017), value co-creation (Camilleri and Neuhofer 2017), and online reputation (Abrate and Viglia 2019; Liang et al. 2017; Zervas, Proserpio, and Byers 2015). These various research streams in turn produce different conceptualizations. In hospitality settings, the sharing economy mainly refers to peer-to-peer accommodations. As Tussyadiah (2016, 70) states, peer-to-peer accommodations allow "regular people, who are distinct from typical business entities, to offer hospitality (by renting out their spare bedrooms or unoccupied properties) to their peers (i.e., tourists)."

Social utility drives these peer-to-peer transactions (Guttentag et al. 2017; Habibi, Kim, and Laroche 2016; Ikkala and Lampinen 2015; Zhu, So and Hudson 2017), because the act of sharing represents "a step toward creating social connection and community" (Albinsson and Yasanthi Perera 2012, 311). Contrary to traditional market-based exchanges, in peer-to-peer transactions, service providers take part in consumers' experiences (Tussyadiah 2016). Societal risks thus arise (Malhotra and Van Alstyne 2014), because when the transaction counterpart is a stranger, consumers experience greater social distance (Schreiner and Kenning 2016). This social distance intensifies their perceived risks and may impede the transaction (Ert, Fleischer, and Magen 2016; Linke 2012; Schreiner and Kenning 2016).

Construal-level theory (Trope and Liberman 2003) provides a theoretical framework for understanding such social distance. In CLT, psychological distance refers to the subjective experience of considering something close or far from the self. It spans multiple dimensions, including temporal (i.e., present vs. distant future), spatial (i.e., 
close vs. distant), and social (i.e., degree of personal connection) distances. The social dimension of psychological distance explains closeness between individual entities (Trope and Liberman 2003), and people tend to exhibit more sympathetic reactions when they feel psychologically closer to others (Linke 2012; Small and Simonsohn 2008). Companies similarly can be represented as close to or distant from consumers (Escalas and Bettman 2005).

Distant objects affect predictions and guide actions (Dhar and Kim 2007; Trope and Liberman 2010; Trope, Liberman, and Wakslak 2007). The CLT proposes that people elaborate abstract mental construals to represent psychologically distant objects and go beyond the immediate situation (Trope and Liberman 2010). Online information might help create an abstract mental construal about the transaction that can assist users in making current decisions about a distant outcome. In this process, they overcome the social distance that exists between them and the potential service provider (Schreiner and Kenning 2016). In online transactions in particular, social distance affects purchase decisions (Darke et al. 2016), which tend to be driven by affective concerns (Han, Lerner, and Keltner 2007). Sensing psychological closeness enhances the affective intensity of the transaction; a psychologically distant mindset instead undermines these affective elements (Williams, Stein, and Galguera 2013). Reducing psychological distance thus should boost the social proximity between the seller and consumer and encourage purchases (Darke et al. 2016).

In sharing accommodation interactions, the host and guest initially are strangers (Tussyadiah and Pesonen 2016), so they both face reputational and societal risks (Malhotra and Van Alstyne 2014). Online communication helps consumers anticipate future in-person interactions (Gibbs, Ellison, and Heino 2006), though traditional reputation cues do not seem to alleviate uncertainty concerns, due to the presence of 
severe reviewing biases (Zervas et al. 2017). Similar to corporate brands in traditional marketplaces, personal self-presentations might serve to disclose fine-grained information and reduce perceived risks (Gibbs, Ellison, and Heino 2006). To measure the role of different self-presentation strategies on the effectiveness of transactions, we consider seller revenues as our outcome variable, an encompassing measure that combines prices and occupancy into a single indicator.

\subsection{Self-presentation: Social-oriented content to boost revenues}

In online communication, personal profiles offer key information (Ellison, Hancock, and Toma 2012; Uski and Lampinen 2016). Websites communicate with known and unknown others (Schau and Gilly 2003), and information displayed on sellers' profiles allows potential consumers to gauge their reputations (You, Vadakkepatt, and Joshi 2015). Personal information becomes especially pertinent in sharing contexts (Belk 2014). A wide range of personal profile attributes contribute to trust and reputation building in these transactions, including the seller's photo (Ert, Fleischer, and Magen 2016; Xu 2014), full identification (Edelman and Luca 2014) and sellers'selfpresentation patterns (Ma et al. 2017; Tussyadiah and Park 2018).

Goffman (1959) refers to self-presentations as the continuous strategic expression of the self. In conveying self-image to others, self-presentations are a critical component of social interaction (Goffman 1959; Schlenker 1980). Online, individual users present themselves to project a desired impression, and this digital self is essential to interpersonal communications (Schau and Gilly 2003). The level of social distance between two parties can be measured by the intensity of their interpersonal communication (Giles and Ogay 2007); and it has a significant role in trust building. Trustworthiness increases when people are socially closer (Glaeser et al. 2000). Because 
expressing and sharing personal information attenuates psychological distance between parties, it also can create trusting beliefs (Toma and D'Angelo 2015).

In online communities, users create and share identities through profile selfpresentations (Chen 2013). As previous studies show, compelling self-presentations determine consumer choices (Larrimore et al. 2011; Ma et al. 2017) and contribute to transaction effectiveness (Weinberg et al. 2013). Specifically, a seller's self-presentation can increase the popularity of her or his listings by $8 \%$ (Mauri et al. 2018). A compelling self-presentation is essential to building an identity (Pera, Viglia, and Furlan 2016) and creating emotional and cognitive states of connection with consumers (Bhattacharya and Sen 2003; Woodside, Sood, and Miller 2008).

Different self-presentation patterns also evoke varying levels of trust and purchase intentions. Particularly, consumers' booking intentions are higher when the host selfpresents as well-traveled rather than as a worker (Tussyadiah and Park 2018), suggesting that a relational self-presentation (i.e., showing competence in hosting guests, highlighting empathy and social connections) enhances the bond between host and guest and results in greater trust and booking intentions. Guests also report increasingly looking for meaningful social interactions with hosts (Tussyadiah and Pesonen 2016).

Socialization refers to processes by which people from varied cultures and communities achieve a harmonious group existence, in social, emotional, and cognitive domains (Maccoby 2007). We embrace this conceptualization and focus on social values and their role in creating a human bond between host and guest. Social contact and cultural distance effectively define customer value and travel experiences (Fan et al. 2017; Zhang, Gu, and Jahromi 2019). By disclosing information about the type of relationship and the level of interactions between host and guest, a social-oriented self-presentation 
might mitigate the social distance that guests perceive regarding the experience (i.e., staying at that place). Hosts thus might emphasize their ability to provide meaningful experiences, such as a willingness to interact with and support guests (e.g., offering a nice welcoming experience, involving them in the community).

Building on these arguments, we predict that promoting social themes in a selfpresentation may mitigate the social distance between parties and facilitate peer-to-peer transactions. Schreiner and Kenning (2016) similarly report a diminished sharing ratio as social distance increases. Overcoming social distance in the transaction should result in more concrete construals of the host. Because social elements are key to establishing demand (Ert, Fleischer, and Magen 2016; Liang et al. 2017; Tussyadiah and Pesonen 2016) and maximizing revenue (Abrate and Viglia 2019), we predict that the more the content in the seller's self-presentation is social (i.e., appealing to social values), the higher sellers' revenues should be. Formally,

H1: A social-oriented self-description has a positive effect on sellers' revenues.

2.2 Information overload effects of self-presentations on revenues

Berger and Calabrese (1975) recommend reducing uncertainty by increasing the amount of available information. In online interactions, consumers perceive information disclosure as useful (Bazarova and Choi 2014; Gibbs, Ellison, and Lai 2011; Racherla and Friske 2012). It also relates closely to willingness to pay (e.g., Huang, Zhu, and Zhou 2013). To reduce uncertainty, a longer and detailed description can be effective; Flanagin (2007) finds that longer descriptions correlate with increased bids and higher selling prices on eBay, and Larrimore et al. (2011) reveal that the number of words in self-presentations is a significant predictor of funding success on an online peer-to-peer 
lending platform. Likewise, Ma et al. (2017) suggest that longer self-disclosures are perceived as more trustworthy.

However, research into information effects in consumer decision-making also reveals that too much information can lead to information overload (Lurie 2004; Messner and Wänke 2011). Humans have limited cognitive resources and allocate them judiciously (Payne 1982). Compared with an alternative that requires more effort to judge, an option that requires less cognitive effort is mostly preferred (Garbarino and Edell 1997). Decision quality decreases when there is too much information, because consumers struggle to process it (Lee and Lee 2004; Malhotra 1982). In online settings, consumers can access infinite amounts of information, so the optimal length of presentations is a critical question (Aljukhadar, Senecal, and Daoust 2012). Previous studies suggest an inverted U-shaped relationship between the amount of information and the degree of information processing (Sicilia and Ruiz 2010). According to Lee and Lee (2004), information overload leaves consumers less satisfied, less confident, and more confused. As the required cognitive effort increases, the likelihood of the difficult alternative being selected also tends to be lower (Garbarino and Edell 1997). Issues with information overload are especially salient in the tourism domain, preventing consumers from making online bookings (Lu, Gursoy, and Lu 2016).

Following these premises regarding the optimal length of self-presentations, we propose that revenues initially increase as self-presentation length increases. However, after a threshold, revenues diminish, due to consumers' inability to process the excessive information efficiently. This shift leads to a lower likelihood of selecting listings with overly long self-presentations, resulting in a negative revenue effect. Formally, 
H2: The effect of self-presentation length on sellers' revenues follows an inverted Ushape.

\section{Methodology}

\subsection{Data}

The empirical context for this study is Airbnb, the largest peer-to-peer platform in the tourism accommodation sector (Guttentag 2015). Airbnb is growing at a rapid rate and currently represents a major player in the hospitality industry (Zaleski 2017), with more than 3 million global listings in nearly 200 countries, and approximately 200 million registered guests (Airbnb 2017).

The study relies on two different data sources. First, we retrieved information about all Airbnb private rooms in Manhattan (New York) and London from Insideairbnb.com (2017), an independent website that provides data sourced from public information available on Airbnb.com. Second, we gathered revenue data from AirDNA (2017). By tracking daily calendar and booking information on Airbnb listings, AirDNA collects data about daily rates, occupancy rates, seasonal demand, and revenues generated by short-term rentals. For the purpose of the present study, the AirDNA database comprises hosts' actual revenues for each Airbnb listing over the previous 12 months.

Because self-presentation is important to create a social bond with guests, we investigate "private room" listings, where the host and guest share spaces. To guarantee that the sample does not contain property dealers ("business" hosts), whose performance outweighs that of ordinary hosts (Gunter 2018), we removed any listings for which the host manages more than two listings. In addition, as in Miller (1997), the sample comprises only listings whose self-presentation contains more than 30 words, to ensure the self-presentation is long enough to be meaningful. Finally, to avoid within- 
city location effects for revenues, as in Abrate and Viglia (2019), we collected just listings within a 3-kilometer distance of the main touristic attraction. The multistage sampling procedure starts with the selection of the investigated city and then selects the individual collection of Airbnb listings that match the key criteria.

The final data set consists of 6,074 Airbnb listings in New York $(n=1,497)$ and London $(\mathrm{n}=4,577)$. These two cities are top destinations in North America and Europe, respectively (GDCI 2017). In addition, they are similar, in that they both attract business and tourism travelers throughout the year, which helps us avoid seasonality patterns in the revenues.

\subsection{Data analysis}

We use a two-step methodological approach to analyze the effect of self-presentation strategies on hosts' revenues. First, we use latent topic modeling to categorize the content of self-presentations by semantics. Second, with multiple regression analysis, we test the hypotheses.

\subsubsection{Latent Topic Modeling}

The latent Dirichlet allocation (LDA) technique is a latent topic modeling approach that uses a Bayesian learning algorithm to capture the underlying dimensions in a set of documents (Blei, Andrew, and Michael 2003). The topic model assumes that latent dimensions (i.e., topics) are distributed over a vocabulary of words that people use in descriptions (Tirunillai and Tellis 2014). In addition, the LDA algorithm adjusts the relative importance of topics in documents and words in topics iteratively. The words in each document get independently extracted from different "boxes," each containing some set of words. Topics generally are shared among documents, and every document features its own mixture of topics. According to LDA, the dimensionality k of the 
Dirichlet distribution, or the number of topics to be extracted, is known and fixed. Researchers can predefine the number of topics to extract $(K)$.

Recent tourism research has used LDA to extract dimensions from online reviews (Guo, Barnes, and Jia 2017). We follow this line, for two main reasons. First, LDA can analyze large-scale data. Second, it calculates the frequency of occurrence of each extracted dimension per document, which facilitates the validation of the results. Therefore, for this study, we assume that $N$ is the sequence of words that constitutes a self-presentation, referred to as a document. The set of documents (i.e., corpus) contains $M$ self-presentations.

Guo et al. (2017) provide a detailed explanation of the hierarchical topic model process, which we also illustrate in Figure 1. The $\mathrm{W}_{\mathrm{ij}}$ circle represents observable variables (i.e., words in self-presentations). Circles $\mathrm{Z}_{\mathrm{ij}}$ and $\theta_{\mathrm{i}}$ refer to latent variables, such that $\mathrm{Z}_{\mathrm{ij}}$ is the topic for the $j$-th word in document $i$, and $\theta_{\mathrm{i}}$ represents the topic distribution per document $i$. The inner circle shows the repeated choice of words and topics within a document; the outer one refers to documents. In addition, $\varphi_{\text {zij }}$ represents the word distribution per topic $K$. The boxes are the replications. Thus LDA entails the following generative process for each document in a corpus:

1. Choose $N \sim$ Poisson $(\xi)$.

2. Choose $\theta \sim \operatorname{Dir}(\alpha)$.

3. For each of the $N$ words $\mathrm{w}_{\mathrm{n}}$ :

(a) Choose a topic $z_{n} \sim \operatorname{Multinomial}(\theta)$.

(b) Choose a word $\mathrm{w}_{\mathrm{n}}$ from $\mathrm{p}\left(\mathrm{w}_{\mathrm{n}} \mid \mathrm{z}_{\mathrm{n}}, \beta\right)$, a multinomial probability conditioned on the topic $\mathrm{Z}_{\mathrm{n}}$. 
In this process, $\mathrm{z}$ and $\theta$ refer to latent variables, $N$ is the length of documents, and $\alpha$ and $\beta$ are hyper-parameters at the corpus level inferred using Gibbs sampling methods (Griffiths and Steyvers 2004).

\section{[Insert Figure 1 around here]}

To conduct the LDA analysis, we used the packages "tm," "SnowballC," and "topicmodels" of the R statistical software. The first step consists of eliminating nonEnglish words, tokenization, word stemming, and stopwords. Next, the algorithm extracts the $K$ dimensions and allocates words to topics iteratively.

\subsubsection{Multiple regression analysis}

After LDA identifies the emerging topics, we use multiple regression analysis to measure the effect of these topics on hosts' revenues. The dependent variable is hosts' revenues (over the previous 12 months). Five independent variables, one per topic, come from the LDA $(\mathrm{Ti}$, where $\mathrm{i}=1, \ldots, \mathrm{k})$ and represent the degree in which each selfpresentation relates to each topic in its content. That is, Ti reflects the proportion of the content that relates to topic $\mathrm{i}$. LDA assumes that $\sum_{i=1}^{k} T i=1$, therefore we run different regressions, each with one independent variable, which reduces multicollinearity concerns.

Finally, to test the effect of self-presentation length on revenues, the analysis includes the number of words $(\mathrm{NoW})$ as another independent variable. To account for the effect of the listing characteristics, we include several control variables in the regression too.

\section{Results}

Table 1 presents the descriptive statistics of the listings. AirDNA (2017) uses U.S. dollars to record prices and performance in both countries. The annual revenue is around $\$ 8,334$, with values ranging from $\$ 23$ to more than $\$ 120,000$. The overall 
average rating is 4.75 , and listings earn an average of 34 guest reviews. On average, hosts show 14 pictures of the accommodation and include a self-presentation with 82 words. Finally, $26.6 \%$ of hosts have earned "Superhost" status, meaning that they receive 5 -stars in at least $80 \%$ of their reviews.

[Insert Table 1 around here]

\subsection{LDA analysis}

With the preliminary analysis of the data, we predefine the number of topics to extract ( $\mathrm{k}$ parameter), by setting the $\mathrm{k}$ parameter to different levels $(\mathrm{k}=1, \ldots, 10)$. Low $\mathrm{k}$ values (i.e., $\mathrm{k}=1, \ldots, 3)$ result in broad classifications of the content; high $\mathrm{k}$ values $(\mathrm{k}=$ $7, \ldots, 10)$ result in very narrow topics. Three judges independently examined the results of the 4-, 5-, and 6-topic solutions and agreed that the 5-topic solution was the most consistent. Thus, Table 2 presents the results of the LDA analysis for the 5-topic solution, including the ten most frequent words per topic. In some cases, a word is truncated, such that it represents a group of terms with the same root.

[Insert Table 2 around here]

The final topic classifications are "House and local area," "Social values," "Host's job and details," "Interests and tastes," and "Travel habits," which align with previous research. For example, we compare these emerging topics with the dimensions extracted by Ma et al. (2017), who coded the sentences in Airbnb profiles to estimate the relationship between self-disclosure and perceived trustworthiness. For their coding scheme, Ma et al. (2017) began with topics that the Airbnb interface suggests hosts should use. Using qualitative data analysis software and annotators from Amazon Mechanical Turk to validate their results, they identify the following topics: "Interests and tastes," "Life motto and values," "Work and education," "Relationships," 
"Personality," "Origin or residence," "Travel," and "Hospitality." These results match our LDA dimensions well.

To check the ecological validity of the findings, we selected a random sample of 50 self-descriptions. Three judges independently analyzed their content to identify the most salient topic in each self-presentation. Their results were consistent, reaching agreement about the predominant topic in $81 \%$ of the self-descriptions. Next, we compared their results with the output of the LDA analysis, which revealed the topic with highest percentage of occurrence in each self-presentation. The judges' solutions matched the LDA output for more than $90 \%$ of the self-presentations.

\subsection{Regression analysis}

Table 3 contains the results of the regression analysis. The effect of "Social values" (T2) on hosts' revenues is positive $(p<.01)$; when self-presentation content focuses on the experience's social aspect, revenues are higher. This topic refers to social values on the Airbnb platform and includes words that represent interactions or a sense of community, such as "welcome," "share," and "home." Conversely, the effect of "Interest and tastes" (T4) on revenues is negative. The other topics do not have significant effects on hosts' revenues (T1, T3, and T5). These results offer support for H1. A self-presentation that evokes social aspects of the experience (i.e., interaction with guests, sharing community) leads to higher revenues.

We also find a positive effect of the number of words (i.e., self-description length) on hosts' revenues, in support of H2. As illustrated in Figure 2, this effect is significant and quadratic, following an inverted U-shaped function. As the number of words increases, hosts' revenues increase up to a point (i.e., number of words $=424$ ). Beyond this threshold, revenues start decreasing. Table 4 shows that these results hold when we 
include the entire set of topics in one single regression (excluding T1, to avoid linear dependency among the regressors).

[Insert Tables 3 and 4 around here]

[Insert Figure 2 around here]

\section{Discussion}

A self-presentation strategy that reduces social distance positively affects sellers' revenues. Enhancing expectations about the host-guest relationship helps create a social bond between the guest and host prior to the experience. A self-presentation focused on the host's personal interests instead has a negative effect on revenues. On the one hand, this finding may stem from the lack of social closeness that potential guests perceive from such a self-presentation. Stressing specific personal hobbies or tastes may signal a self-centered or individualistic approach to the sharing activity. On the other hand, disclosing information about the host's own interests and tastes could reveal a mismatch with guests' preferences. Although possible, an exact match of the host's and guest's interests is unlikely, especially if hosts embrace niche activities.

Our findings also reveal an inverse U-shaped effect of self-presentation length on revenues; providing more information increases sellers' revenues up to a point, but then the effect of the number of words on revenues becomes negative. That is, there is an optimal threshold length for self-presentations, so that hosts achieve the highest revenues when their self-descriptions are about 424 words in length. After this point, longer self-descriptions lead to decreasing returns. As proposed in previous studies (e.g., Messner and Wänke 2011; Sicilia and Ruiz 2010), providing consumers with too much information results in suboptimal decision-making processes, in line with both 
information overload (Lurie 2004; Messner and Wänke 2011) and cognitive effort (Garbarino and Edell 1997) theories. On Airbnb, an alternative that requires more cognitive effort will be chosen less frequently than an alternative that is easier to evaluate.

\subsection{Theoretical and practical implications}

This paper contributes to extant theory in at least three ways. First, noting the existence of different self-presentation patterns in peer-to-peer marketplaces (Tussyadiah and Park 2018), we posited that self-presentation strategies affect sellers' revenues, such that a social-oriented self-presentation can boost revenues. This finding adds support to the growing body of research that stresses social values' key role in peer-to-peer trading (Lutz and Newlands 2018; Tussyadiah and Pesonen 2016; Zhang, Gu, and Jahromi 2019). Self-presentation length also affects revenues, following an inverted U-shape that reaches its peak at 424 words. This result provides measurable evidence for lingering questions about the effects of information overload (Lee and Lee 2004; Lu, Gursoy, and Lu 2016; Messner and Wänke 2011).

Second, this study contributes to CLT literature (Trope and Liberman 2010). Our findings suggest that including content that enhances social closeness in selfpresentations is a good strategy to reduce psychological distance between the seller and consumer. They thus provide additional support to studies that emphasize social distance as an underlying mechanism of sharing behavior (Schreiner and Kenning 2016). This study also responds to calls for research that applies decision-making perspectives to peer-to-peer interactions (Yadav and Pavlou 2014).

Third, analyzing self-presentations by extracting online discourses through latent topic modeling represents another unique contribution of this research. Previous studies focus 
on quantitative variables such as online ratings or the presence of specific attributes; research on sellers' self-presentations is scant though (Tussyadiah and Park 2018).

From a managerial perspective, self-presentations offer a powerful instrument to promote peer-to-peer accommodations, a finding that is particularly relevant for ordinary hosts who have limited resources to promote their services (Blazevic et al. 2013). Self-presentations can be a powerful personal branding tool (Kim and Tussyadiah 2013; Labrecque, Markos, and Milne 2011), and with this study, we offer two clear implications for hosts. First, they should include social values content in their self-presentation to maximize revenues. Their self-presentations should reveal details about their expected interactions with their guests and emphasize their ability to provide meaningful experiences, such as signaling their willingness to interact with and support them (e.g., offering a nice welcoming experience, involving them in the community). With a social-oriented self-presentation, hosts can enrich the social bond with potential guests, create memorable experiences (Kim and Chen 2018), and boost their revenues. This recommendation extends broadly to other peer-to-peer platforms that involve interactions of seller and consumer, like car and meal sharing sites.

Second, this research provides actionable levers regarding the optimal length of the selfpresentation. Empirically, our data indicate an optimal length of 424 words. For hosts, this level of detail seems sufficient to establish a sense of social bonding with guests. A longer self-presentation would backfire in terms of revenue maximization. Accordingly, online platforms might establish constrained spaces to assist sellers.

The findings also have implications for traditional hospitality operators. Hotels are reacting relatively slowly to the disruptive effects of peer-to-peer trading. In view of the social motivations that prompt consumers to use peer-to-peer accommodations, they 
might benefit from targeting social-oriented consumers and offering experiences that focus on human connections. Encoding more social and personal elements seems a likely future development for the traditional hospitality industry (Tasiello, Viglia, and Mattila 2018); recent hotel campaigns already have started emphasizing these social values (e.g., Marriott 2017).

\subsection{Limitations and further research}

The present research is not without limitations. First, analyzing the content of selfpresentations with word analysis software might pose accuracy concerns regarding the allocation of terms to topics. Although the LDA technique has been used successfully in prior tourism research (Guo, Barnes, and Jia 2017), it categorizes content without human input. Second, a qualitative approach to explore the storytelling elements in selfpresentations (e.g., Pera, Viglia, and Furlan 2016) could provide more fine-grained data pertaining to the structure plot of presentations and go beyond a mere analysis of content. Storytelling is central to a deeper understanding of consumer psychology (Bahl and Milne 2010; Dessart 2018; Escalas and Stern 2003). Third, our sample only spans two Western cities; it would be interesting to include destinations where hosts have different cultural backgrounds.

Several other aspects also remain to be investigated. Similarity theory (Naylor, Lamberton, and Norton 2011) might provide another compelling framework to analyze how social distance is perceived differently at the individual level. Using this framework, an experimental approach could manipulate hosts' presentation and then measure individual travelers' choices. Furthermore, this research focuses on the role of self-presentation strategies on income generation, in accordance with the increasing attention to revenue maximization in the sharing economy (Abrate and Viglia, 2019). However, we acknowledge that a strong similarity between host and guest might 
increase transaction likelihood (Kwok and Xie 2018). On this note, a host that focuses on a better fit with a guest might decide to accept very few bookings. Future research might use the fit between the guest and host as an alternative dependent variable.

Airbnb has recently implemented a new feature that enables users to present their profiles in a video format. Visual information magnifies social presence online (Xu 2014), so additional research might investigate the revenue effects of multimedia selfpresentations. An extension of this analysis could include a comparison of the selfpresentation patterns on other hospitality platforms (e.g., HomeAway, Booking.com, Tripadvisor.com).

\section{Conclusion}

The emergence of peer-to-peer platforms has transformed the nature of transactions (Figueiredo and Scaraboto 2016; Sigala 2017). The resulting marketplaces focus on access-based consumption and challenge the dominance of ownership and possessions as the ultimate goals of consumption (Bardhi and Eckhard 2017). This new paradigm has significantly affected the tourism and hospitality industry, which has thus undergone a unique transformation. These marketplaces have empowered individual users who can market their own products. Increasing their marketing literacy is a key agenda issue (Benoit et al. 2017; Sundararajan 2014). Despite initial research emphasizing the relevance of strategically managing information (Caldieraro et al. 2018), clear guidance for sellers is scant.

Our findings address this gap by specifying the revenue impact of different selfpresentation strategies in peer-to-peer platforms. Social values are key dimensions of the customer value proposition, as predicted by Zhang, Gu, and Jahromi (2019). We provide evidence that to boost the human bond with potential guests, hosts' self- 
presentations should focus on the social aspect of their relationship. Because social interactions contribute to creating memorable travel experiences (Kim and Chen 2018), emphasizing hosts' willingness to interact with guests can positively affect their revenues. 
References

Abrate, Graziano and Giampaolo Viglia. 2019. "Personal or Product Reputation?

Optimizing Revenues in the Sharing Economy." Journal of Travel Research 58 (1): 136148.

Airbnb. 2017. “About Us.” https://www.airbnb.ca/about/about-us (accessed November 24, 2017)

AirDNA. 2017. “About AirDNA.” https://www.airdna.co/about (accessed November $24,2017)$

Albinsson, Pia A. and B. Yasanthi Perera. 2012. "Alternative Marketplaces in the 21st Century: Building Community through Sharing Events." Journal of Consumer Behaviour 11 (4): 303-315.

Aljukhadar, Muhammad, Sylvain Senecal, and Charles-Etienne Daoust. 2012. "Using Recommendation Agents to Cope with Information Overload." International Journal of Electronic Commerce 17 (2): 41-70.

Bahl, Shalini and George R. Milne. 2010. "Talking to Ourselves: A Dialogical Exploration of Consumption Experiences." Journal of Consumer Research 37 (1): 176195.

Bardhi, Fleura and Giana M. Eckhardt. 2012. "Access-Based Consumption: The Case of Car Sharing." Journal of Consumer Research 39 (4): 881-898.

Bardhi, Fleura, and Giana M. Eckhardt. 2017. "Liquid consumption." Journal of Consumer Research 44 (3): 582-597.

Bazarova, Natalya N. and Yoon Hyung Choi. 2014. "Self-Disclosure in Social Media: Extending the Functional Approach to Disclosure Motivations and Characteristics on Social Network Sites." Journal of Communication 64 (4): 635-657. 
Belk, Russell. 2014. "You are what You can Access: Sharing and Collaborative Consumption Online." Journal of Business Research 67 (8): 1595-1600.

Benoit, Sabine, Thomas L. Baker, Ruth N. Bolton, Thorsten Gruber, and Jay Kandampully. 2017. "A Triadic Framework for Collaborative Consumption (CC): Motives, Activities and Resources \& Capabilities of Actors." Journal of Business Research. 79: 219227

Berger, Charles R. and Richard J. Calabrese. 1975. "Some Explorations in Initial Interaction and Beyond: Toward a Developmental Theory of Interpersonal Communication." Human Communication Research 1 (2): 99-112.

Bhattacharya, Chitrabhan B. and Sankar Sen. 2003. "Consumer-Company Identification: A Framework for Understanding Consumers' Relationships with Companies." Journal of Marketing 67 (2): 76-88.

Blazevic, Vera, Wafa Hammedi, Ina Garnefeld, Roland T. Rust, Timothy Keiningham, Tor W. Andreassen, Naveen Donthu, and Walter Carl. 2013. "Beyond Traditional Word-of-Mouth: An Expanded Model of Customer-Driven Influence." Journal of Service Management 24 (3): 294-313.

Blei, David M., Andrew Y. Ng, and Michael I. Jordan. 2003. "Latent Dirichlet Allocation." Journal of Machine Learning Research 3 (Jan): 993-1022.

Botsman, Rachel. 2014. "Sharing's Not just for Start-Ups." Harvard Business Review 92 (9): 23-25.

Botsman, Rachel and Roo Rogers. 2011. What's Mine is Yours: How Collaborative Consumption Is Changing the Way We Live. London: Collins.

Caldieraro, Fabio, Jonathan Zhang, Marcus Cunha Jr., and Jeffrey D. Shulman. 2018. "Strategic Information Transmission in Peer-to-Peer Lending Markets." Journal of Marketing 82 (2): 42-63. 
Camilleri, Jeannette and Barbara Neuhofer. 2017. "Value Co-Creation and Co-

Destruction in the Airbnb Sharing Economy." International Journal of Contemporary Hospitality Management 29 (9): 2322-2340.

Chen, Chih-Ping. 2013. "Exploring Personal Branding on YouTube." Journal of Internet Commerce 12 (4): 332-347.

Cheng, Mingming. 2016. "Current Sharing Economy Media Discourse in Tourism." Annals of Tourism Research 60 (C): 111-114.

Darke, Peter R., Michael K. Brady, Ray L. Benedicktus, and Andrew E. Wilson. 2016. "Feeling Close from Afar: The Role of Psychological Distance in Offsetting Distrust in Unfamiliar Online Retailers." Journal of Retailing 92 (3): 287-299.

Dessart, Laurence. 2018. "Do Ads that Tell a Story always Perform Better? The Role of Character Identification and Character Type in Storytelling Ads." International Journal of Research in Marketing 35 (2): 289-304.

Dhar, Ravi and Eunice Y. Kim. 2007. "Seeing the Forest Or the Trees: Implications of Construal Level Theory for Consumer Choice." Journal of Consumer Psychology 17 (2): 96-100.

Dolnicar, Sara. 2017. Peer-to-Peer Accommodation Networks: Pushing the Boundaries. Oxford: Goodfellow Publishers.

Edelman, Benjamin, and Michael Luca. 2014. "Digital discrimination: The case of Airbnb. com." Harvard Business School NOM Unit Working Paper 14-054. Edelman, Benjamin, Michael Luca, and Dan Svirsky. 2017. "Racial Discrimination in the Sharing Economy: Evidence from a Field Experiment." American Economic Journal: Applied Economics 9 (2): 1-22. 
Ellison, Nicole B., Jeffrey T. Hancock, and Catalina L. Toma. 2012. "Profile as Promise: A Framework for Conceptualizing Veracity in Online Dating SelfPresentations." New Media \& Society 14 (1): 45-62.

Ert, Eyal, Aliza Fleischer, and Nathan Magen. 2016. "Trust and Reputation in the Sharing Economy: The Role of Personal Photos in Airbnb." Tourism Management 55: $62-73$.

Escalas, Jennifer Edson and James R. Bettman. 2005. "Self-Construal, Reference Groups, and Brand Meaning." Journal of Consumer Research 32 (3): 378-389.

Escalas, Jennifer Edson and Barbara B. Stern. 2003. "Sympathy and Empathy: Emotional Responses to Advertising Dramas." Journal of Consumer Research 29 (4): 566-578.

Fan, Daisy XF, Hanqin Qiu Zhang, Carson L. Jenkins, and Pearl MC Lin. 2017. "Does Tourist-Host Social Contact Reduce Perceived Cultural Distance?" Journal of Travel Research 56 (8): 998-1010.

Figueiredo, Bernardo and Daiane Scaraboto. 2016. "The Systemic Creation of Value through Circulation in Collaborative Consumer Networks." Journal of Consumer Research 43 (4): 509-533.

Flanagin, Andrew J. 2007. "Commercial Markets as Communication Markets: Uncertainty Reduction through Mediated Information Exchange in Online Auctions." New Media \& Society 9 (3): 401-423.

Forman, Chris, Anindya Ghose, and Batia Wiesenfeld. 2008. "Examining the Relationship between Reviews and Sales: The Role of Reviewer Identity Disclosure in Electronic Markets." Information Systems Research 19 (3): 291-313.

Garbarino, Ellen C., and Julie A. Edell. 1997. "Cognitive Effort, Affect, and Choice." Journal of Consumer Research 24(2): 147-158. 
GDCI (Global Destination Cities Index). 2017. "Origin markets.” https://newsroom.mastercard.com/wp-content/uploads/2017/09/Origin-Markets-forTop-5-Cities-per-Region.pdf (accessed November 24, 2017)

Gebbia, J. 2016. "How Airbnb Designs for Trust." https://www.ted.com/speakers/joe_gebbia (accessed October 10, 2018)

Gibbs, Jennifer L., Nicole B. Ellison, and Rebecca D. Heino. 2006. "Self-Presentation in Online Personals: The Role of Anticipated Future Interaction, Self-Disclosure, and Perceived Success in Internet Dating." Communication Research 33 (2): 152-177.

Gibbs, Jennifer L., Nicole B. Ellison, and Chih-Hui Lai. 2011. "First comes love, then comes Google: An investigation of uncertainty reduction strategies and self-disclosure in online dating." Communication Research 38 (1): 70-100.

Giles, Howard, and Tania Ogay. 2007. "Communication accommodation theory." In Explaining Communication: Contemporary Theories and Exemplars, edited by B. B. Whaley and W. Samter, 293-310. Mahwah, NJ: Lawrence Erlbaum.

Glaeser, Edward L., David I. Laibson, Jose A. Scheinkman, and Christine L. Soutter. 2000. "Measuring trust." The Quarterly Journal of Economics 115 (3): 811-846.

Goffman, Erving. 1959. "The Moral Career of the Mental Patient." Psychiatry 22 (2): 123-142.

Griffiths, T. L. and M. Steyvers. 2004. "Finding Scientific Topics." In Proceedings of the National Academy of Sciences of the United States of America 101 Suppl 1: 52285235.

Gunter, Ulrich. 2018. "What Makes an Airbnb Host a Superhost? Empirical Evidence from San Francisco and the Bay Area." Tourism Management 66: 26-37. 
Guo, Yue, Stuart J. Barnes, and Qiong Jia. 2017. "Mining Meaning from Online Ratings and Reviews: Tourist Satisfaction Analysis using Latent Dirichlet Allocation." Tourism Management 59: 467-483.

Guttentag, Daniel. 2015. "Airbnb: Disruptive Innovation and the Rise of an Informal Tourism Accommodation Sector." Current Issues in Tourism 18 (12): 1192-1217. Guttentag, Daniel, Stephen Smith, Luke Potwarka, and Mark Havitz. 2017. "Why Tourists Choose Airbnb: A Motivation-Based Segmentation Study." Journal of Travel Research 57 (3): 342-359

Habibi, Mohammad Reza, Andrea Kim, and Michel Laroche. 2016. "From Sharing to Exchange: An Extended Framework of Dual Modes of Collaborative Nonownership Consumption." Journal of the Association for Consumer Research 1 (2): 277-294. Han, Seunghee, Jennifer S. Lerner, and Dacher Keltner. 2007. "Feelings and Consumer Decision Making: The appraisal-tendency Framework." Journal of Consumer Psychology 17 (3): 158-168.

Huang, Minxue, Huawei Zhu, and Xuechun Zhou. 2013. "The Effects of Information Provision and Interactivity on e-Tailer Websites." Online Information Review 37 (6): 927-946.

Ikkala, Tapio and Airi Lampinen. 2015. "Monetizing Network Hospitality: Hospitality and Sociability in the Context of Airbnb." In Proceedings of the 18th ACM conference on computer supported cooperative work \& social computing: 1033-1044.

Insideairbnb. 2017. "Get the data.” http://insideairbnb.com/get-the-data.html (accessed May 24, 2017)

Karlsson, Logi and Sara Dolnicar. 2016. "Someone's been Sleeping in My Bed." Annals of Tourism Research 58: 159-162. 
Kim, Hyangmi and Joseph S. Chen. 2018. "The memorable travel experience and its reminiscence functions.” Journal of Travel Research: 0047287518772366.

Kim, Jeongmi and Iis P. Tussyadiah. 2013. "Social Networking and Social Support in Tourism Experience: The Moderating Role of Online Self-Presentation Strategies." Journal of Travel \& Tourism Marketing 30 (1-2): 78-92.

Koopman, Christopher, Matthew D. Mitchell, and Adam D. Thierer. 2015. "The Sharing Economy and Consumer Protection Regulation: The Case for Policy Change." Journal of Business, Entrepreneurship \& the Law 8 (2): 529.

Kwok, Linchi, and Karen L. Xie. 2018. "Buyer-Seller Similarity: Does It Lead to a Successful Peer-to-Peer Transaction of Room-Sharing Services?" International Journal of Contemporary Hospitality Management 30(9): 2925-2944.

Labrecque, Lauren I., Ereni Markos, and George R. Milne. 2011. "Online Personal Branding: Processes, Challenges, and Implications." Journal of Interactive Marketing 25 (1): $37-50$.

Larrimore, Laura, Li Jiang, Jeff Larrimore, David Markowitz, and Scott Gorski. 2011. "Peer to Peer Lending: The Relationship between Language Features, Trustworthiness, and Persuasion Success." Journal of Applied Communication Research 39 (1): 19-37. Lee, Byung-Kwan and Wei-Na Lee. 2004. "The Effect of Information Overload on Consumer Choice Quality in an on-line Environment." Psychology \& Marketing 21 (3): 159-183.

Liang, Sai, Markus Schuckert, Rob Law, and Chih-Chien Chen. 2017. "Be a "Superhost": The Importance of Badge Systems for Peer-to-Peer Rental Accommodations.” Tourism Management 60: 454-465 
Linke, Lance H. 2012. "Social Closeness and Decision Making: Moral, Attributive and Emotional Reactions to Third Party Transgressions." Current Psychology 31 (3): 291312.

Lu, Allan Cheng Chieh, Dogan Gursoy, and Carol Yi Rong Lu. 2016. "Antecedents and Outcomes of Consumers' Confusion in the Online Tourism Domain." Annals of Tourism Research 57: 76-93.

Lurie, Nicholas H. 2004. "Decision Making in Information-Rich Environments: The Role of Information Structure." Journal of Consumer Research 30 (4): 473-486. Lutz, Christoph, and Gemma Newlands. 2018. "Consumer Segmentation within the Sharing Economy: The Case of Airbnb." Journal of Business Research 88: 187-196. Ma, Xiao, Jeffrey T. Hancock, Kenneth Lim Mingjie, and Mor Naaman. 2017. "SelfDisclosure and Perceived Trustworthiness of Airbnb Host Profiles." In Proceedings of the 2017 ACM Conference on Computer Supported Cooperative Work and Social Computing: 2397-2409.

Maccoby, Eleanor E. 2007. "Historical Overview of Socialization Research and Theory." In Handbook of Socialization: Theory and Research, edited by J. E. Grusec and P. D. Hatings, 13-41. New York: The Guildford Press.

Malhotra, Arvind and Marshall Van Alstyne. 2014. "The Dark Side of the Sharing Economy... and How to Lighten it." Communications of the ACM 57 (11): 24-27. Malhotra, Naresh K. 1982. "Information Load and Consumer Decision Making." Journal of Consumer Research 8 (4): 419-430.

Marriott. 2017. "Marriott International Debuts First-Ever Campaign for New Category Marketing Approach.” http://news.marriott.com/2017/08/marriott-international-debutsfirst-ever-campaign-new-category-marketing-approach/ (accessed November 24, 2017) 
Mauri, Aurelio G., Roberta Minazzi, Marta Nieto-García, and Giampaolo Viglia. 2018. "Humanize Your Business. The Role of Personal Reputation in the Sharing Economy." International Journal of Hospitality Management 73: 36-43.

Messner, Claude and Michaela Wänke. 2011. "Unconscious Information Processing Reduces Information Overload and Increases Product Satisfaction." Journal of Consumer Psychology 21 (1): 9-13.

Miller, M. Mark. 1997. "Frame Mapping and Analysis of News Coverage of Contentious Issues." Social Science Computer Review 15 (4): 367-378.

Naylor, Rebecca Walker, Cait Poynor Lamberton, and David A. Norton. 2011. "Seeing Ourselves in Others: Reviewer Ambiguity, Egocentric Anchoring, and Persuasion." Journal of Marketing Research 48 (3): 617-631.

Payne, John W. 1982. "Contingent Decision Behavior." Psychological Bulletin 92(2): 382.

Pera, Rebecca, Giampaolo Viglia, and Roberto Furlan. 2016. "Who Am I? How Compelling Self-Storytelling Builds Digital Personal Reputation." Journal of Interactive Marketing 35: 44-55.

Pricewaterhouse Coopers. 2016. “Europe’s Five Key Sharing Economy Sectors Could Deliver $€ 570$ Billion by 2025.” https://press.pwc.com/News-releases/europe-s-five-keysharing-economy-sectors-could-deliver--570-billion-by-2025/s/45858e92-e1a7-4466$\underline{\mathrm{a} 011-\mathrm{a} 7 \mathrm{f} 6 \mathrm{~b} 9 \mathrm{bb} 488 \mathrm{f}}$ (accessed November 24, 2017)

Racherla, Pradeep and Wesley Friske. 2012. "Perceived 'Usefulness' of Online Consumer Reviews: An Exploratory Investigation Across Three Services Categories." Electronic Commerce Research and Applications 11 (6): 548-559.

Schau, Hope Jensen and Mary C. Gilly. 2003. "We Are What We Post? SelfPresentation in Personal Web Space." Journal of Consumer Research 30 (3): 385-404. 
Schlenker, Barry R. 1980. Impression Management. Monterey, CA : Brooks/Cole Publishing Company.

Schreiner, Nadine and Peter Kenning. 2016. "To Share or Not to Share? Social Distance as the Underlying Mechanism to Explain Sharing Behavior." In NA - Advances in Consumer Research Volume 44, edited by P. Moreau and S. Puntoni, 758-758. Duluth, MN : Association for Consumer Research.

Sicilia, Maria and Salvador Ruiz. 2010. "The Effect of Web-Based Information Availability on Consumers' Processing and Attitudes." Journal of Interactive Marketing 24 (1): 31-41.

Sigala, Marianna. 2017. "Collaborative Commerce in Tourism: Implications for Research and Industry." Current Issues in Tourism 20 (4): 346-355. Small, Deborah A. and Uri Simonsohn. 2007. "Friends of Victims: Personal Experience and Prosocial Behavior." Journal of Consumer Research 35 (3): 532-542. Sundararajan, Arun. 2014. "What Airbnb Gets About Culture that Uber Doesn't." Harvard Business Review 11.

Tassiello, Vito, Giampaolo Viglia, and Anna S. Mattila. 2018. "How handwriting reduces negative online ratings." Annals of Tourism Research 73: 171-179. Tirunillai, Seshadri and Gerard J. Tellis. 2014. "Mining Marketing Meaning from Online Chatter: Strategic Brand Analysis of Big Data using Latent Dirichlet Allocation." Journal of Marketing Research 51 (4): 463-479.

Toma, Catalina L. and Jonathan D. D’Angelo. 2015. "Tell-Tale Words: Linguistic Cues used to Infer the Expertise of Online Medical Advice." Journal of Language and Social Psychology 34 (1): 25-45. 
Trope, Yaacov and Nira Liberman. 2003. "Temporal Construal." Psychological Review $110(3): 403$

Trope, Yaacov and Nira Liberman. 2010. "Construal-Level Theory of Psychological

Distance." Psychological Review 117 (2): 440.Trope, Yaacov, Nira Liberman, and Cheryl Wakslak. 2007. "Construal Levels and Psychological Distance: Effects on Representation, Prediction, Evaluation, and Behavior." Journal of Consumer Psychology 17 (2): 83-95.

Tussyadiah, Iis P. 2016. "Factors of Satisfaction and Intention to Use Peer-to-Peer Accommodation.” International Journal of Hospitality Management 55: 70-80.

Tussyadiah, Iis P., and Sangwon Park. 2018. "When Guests Trust Hosts for Their Words: Host Description and Trust in Sharing Economy." Tourism Management 67: $261-272$

Tussyadiah, Iis P. and Juho Pesonen. 2016. "Impacts of Peer-to-Peer Accommodation use on Travel Patterns." Journal of Travel Research 55 (8): 1022-1040.

Uski, Suvi and Airi Lampinen. 2016. "Social Norms and Self-Presentation on Social Network Sites: Profile Work in Action." New Media \& Society 18 (3): 447-464.

Weinberg, Bruce D., Ko de Ruyter, Chrysanthos Dellarocas, Michael Buck, and Debbie Isobel Keeling. 2013. "Destination Social Business: Exploring an Organization's Journey with Social Media, Collaborative Community and Expressive Individuality." Journal of Interactive Marketing 27 (4): 299-310.

Williams, Colin C. and Ioana Alexandra Horodnic. 2017. "Regulating the Sharing Economy to Prevent the Growth of the Informal Sector in the Hospitality Industry." International Journal of Contemporary Hospitality Management 29 (9): 2261-2278. 
Williams, Lawrence E., Randy Stein, and Laura Galguera. 2013. "The Distinct

Affective Consequences of Psychological Distance and Construal Level." Journal of Consumer Research 40 (6): 1123-1138.

Woodside, Arch G., Suresh Sood, and Kenneth E. Miller. 2008. "When Consumers and Brands Talk: Storytelling Theory and Research in Psychology and Marketing."

Psychology \& Marketing 25 (2): 97-145.

Xu, Qian. 2014. "Should I Trust Him? The Effects of Reviewer Profile Characteristics on eWOM Credibility." Computers in Human Behavior 33: 136-144.

Yadav, Manjit S. and Paul A. Pavlou. 2014. "Marketing in Computer-mediated Environments: Research Synthesis and New Directions.” Journal of Marketing, 78 (1): $20-40$.

You, Ya, Gautham G. Vadakkepatt, and Amit M. Joshi. 2015. "A Meta-Analysis of Electronic Word-of-Mouth Elasticity." Journal of Marketing 79 (2): 19-39.

Zaleski, O. 2017. “Airbnb Is Said to Double Revenue to \$1 Billion Last Quarter.” https://www.bloomberg.com/news/articles/2017-11-14/airbnb-is-said-to-reach-net-

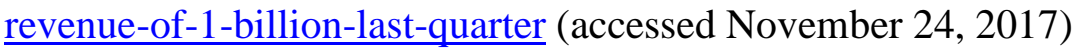

Zervas, Georgios, Davide Proserpio, and John Byers. 2015. "A First Look at Online Reputation on Airbnb, Where Every Stay is Above Average." http://dx.doi.org/10.2139/ssrn.2554500 (accessed October 10, 2018) Zervas, Georgios, Davide Proserpio, and John W. Byers. 2017. "The Rise of the Sharing Economy: Estimating the Impact of Airbnb on the Hotel Industry." Journal of Marketing Research 54 (5): 687-705.

Zhang, Tingting Christina, Huimin Gu, and Melissa Farboudi Jahromi. 2019. "What Makes the Sharing Economy Successful? An Empirical Examination of Competitive Customer Value Propositions." Computers in Human Behavior 95: 275-283. 
Zhu, Ge, Kevin Kam Fung So, and Simon Hudson. 2017. "Inside the Sharing Economy:

Understanding Consumer Motivations Behind the Adoption of Mobile Applications."

International Journal of Contemporary Hospitality Management 29 (9): 2218-2239. 
Figure 1. LDA model (Guo, Barnes, and Jia 2017)

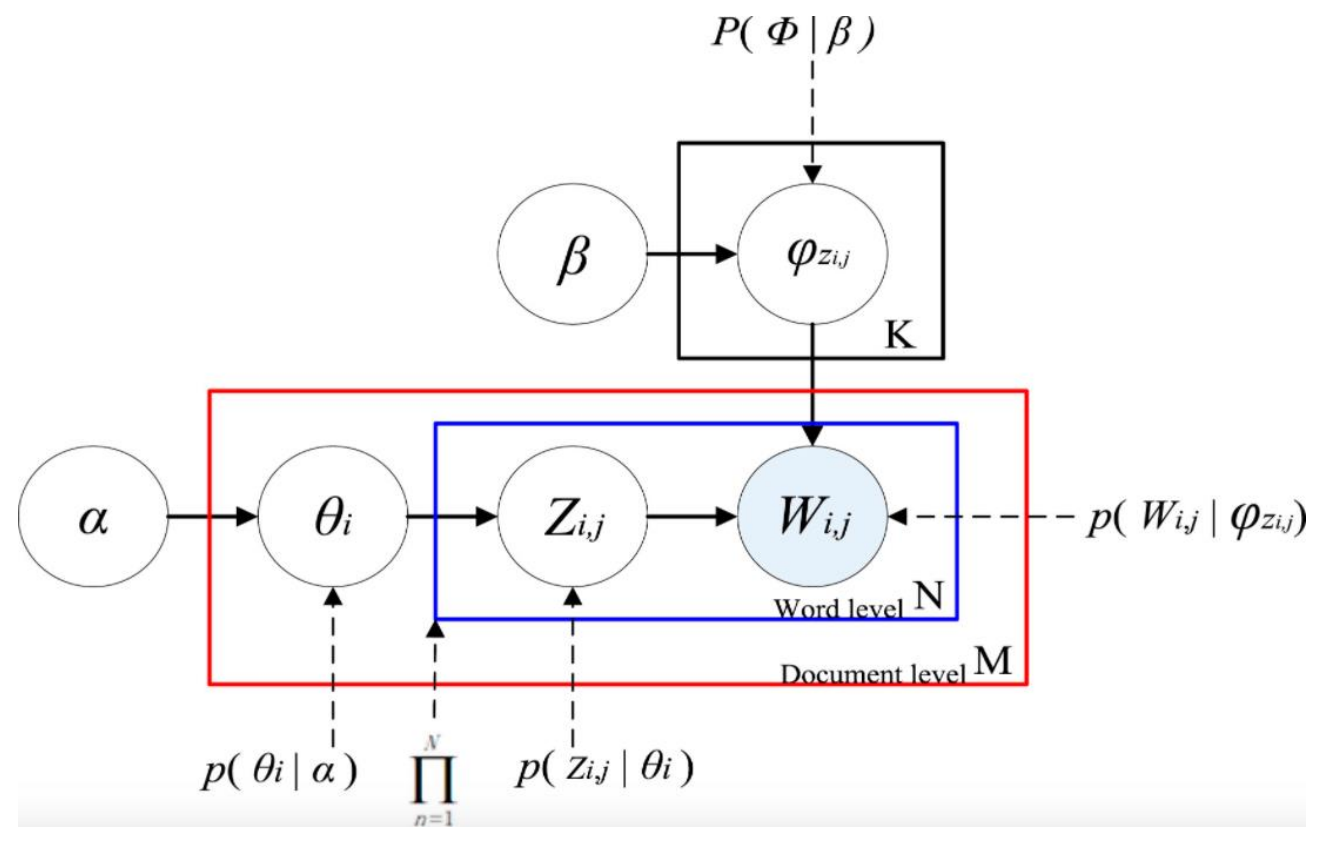

Figure 2. Effect of self-presentation length on revenues

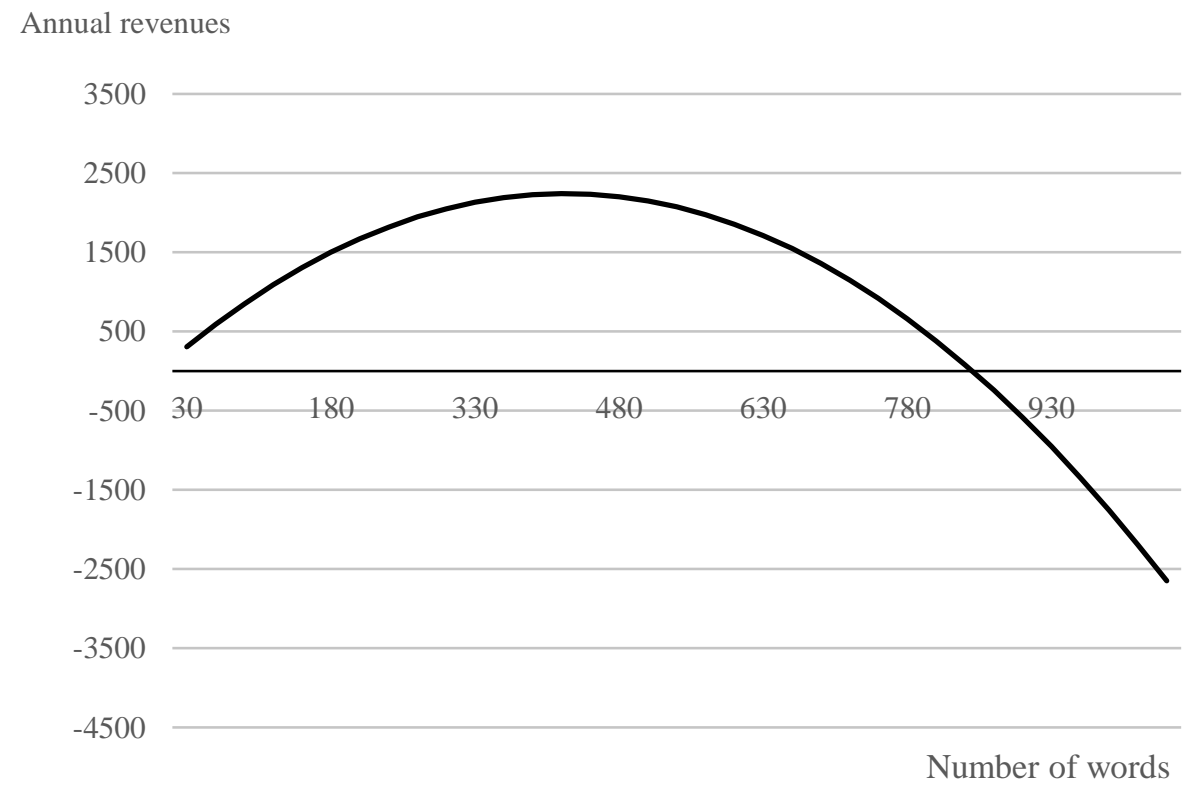


Table 1. Descriptive statistics

\begin{tabular}{|c|c|c|c|c|c|}
\hline Variable & Variable description & Mean & Std. Dev. & Max & Min \\
\hline$\overline{\text { Occup }}$ & Occupancy rate (LTM) & 0.583 & 0.269 & 1.000 & 0.032 \\
\hline$A D R$ & Average daily rate (LTM) & 75.99 & 40.96 & 1328.78 & 16.30 \\
\hline $\operatorname{Rev}$ & Annual revenues (LTM) & $8,333.36$ & $9,148.58$ & 123,576 & 23.00 \\
\hline Kit & Kitchen and breakfast & 91.3 & & & \\
\hline Int & Internet and television & 98.5 & & & \\
\hline Wash & Washer and dryer & 70.3 & & & \\
\hline Swim & Swimming pool and gym & 9.6 & & & \\
\hline Air & Air conditioning and heating & 97.0 & & & \\
\hline Par & Parking & 23.4 & & & \\
\hline$A c c$ & Access & 46.1 & & & \\
\hline Bed & Real bed & 93.0 & & & \\
\hline Ins & Instant bookable & 81.2 & & & \\
\hline Iden & Identity verified & 69.9 & & & \\
\hline Pic & Profile picture & 99.9 & & & \\
\hline Sup & Superhost & 26.6 & & & \\
\hline Can & $\begin{array}{l}\text { Cancellation policy } \\
\text { (mod./strict) }\end{array}$ & 69.8 & & & \\
\hline Rat & Overall rating & 4.75 & 0.29 & 5 & 1 \\
\hline NoR & Number of reviews & 33.5 & 47.22 & 418 & 0 \\
\hline $\mathrm{NoP}$ & Number of pictures & 13.95 & 9.59 & 116 & 1 \\
\hline NoW & Number of words & 82.61 & 58.61 & 1,013 & 30 \\
\hline RLen & Rental length & 5.77 & 4.62 & 94 & 1 \\
\hline$R R$ & Response rate & 93.53 & 19.95 & 100 & 0 \\
\hline$R T$ & Response time (min) & 276.14 & 397.99 & 1,140 & 0.01 \\
\hline \multirow[t]{2}{*}{ City } & City: London & 75.3 & & & \\
\hline & City: NY & 24.7 & & & \\
\hline
\end{tabular}

Notes: In the case of dummy variables, the average value corresponds to the percentage of listings in the sample with that specific characteristic. 
Table 2. Categorization of topics by semantics

\begin{tabular}{|c|c|c|c|c|c|}
\hline & Topic 1 (T1) & Topic 2 (T2) & Topic 3 (T3) & Topic 4 (T4) & Topic 5 (T5) \\
\hline Content & $\begin{array}{l}\text { House and } \\
\text { local area }\end{array}$ & Social values & $\begin{array}{l}\text { Host's job } \\
\text { and details }\end{array}$ & $\begin{array}{l}\text { Interests and } \\
\text { tastes }\end{array}$ & Travel habits \\
\hline \multirow{10}{*}{$\begin{array}{l}\text { Ten most } \\
\text { frequent } \\
\text { words } \\
\text { (descending } \\
\text { order) }\end{array}$} & hous & home & work & enjoy & travel \\
\hline & room & host & art & love & love \\
\hline & walk & guest & interest & friend & peopl \\
\hline & flat & airbnb & profession & like & meet \\
\hline & local & happi & design & music & citi \\
\hline & area & help & old & food & world \\
\hline & restaur & welcom & busi & life & place \\
\hline & away & get & move & time & around \\
\hline & park & share & speak & cook & cultur \\
\hline & beauti & feel & french & read & visit \\
\hline
\end{tabular}


Table 3. Multiple regression analysis

\begin{tabular}{|c|c|c|c|c|c|c|c|c|c|c|c|c|c|}
\hline \multirow[b]{2}{*}{ Type } & \multirow[b]{2}{*}{ Variable } & \multicolumn{2}{|c|}{ Model T1 } & \multicolumn{2}{|c|}{ Model T2 } & \multicolumn{2}{|c|}{ Model T3 } & \multicolumn{2}{|c|}{ Model T4 } & \multicolumn{2}{|c|}{ Model T5 } & \multicolumn{2}{|c|}{ Model NoW } \\
\hline & & $\begin{array}{l}\text { Std. } \\
\text { coef. }\end{array}$ & $\mathrm{t}$ & $\begin{array}{l}\text { Std. } \\
\text { coef. }\end{array}$ & $\mathrm{t}$ & $\begin{array}{l}\text { Std. } \\
\text { coef. }\end{array}$ & $\mathrm{t}$ & $\begin{array}{l}\text { Std. } \\
\text { coef. }\end{array}$ & $\mathrm{t}$ & $\begin{array}{l}\text { Std. } \\
\text { coef. }\end{array}$ & $\mathrm{t}$ & $\begin{array}{l}\text { Std. } \\
\text { coef. }\end{array}$ & $\mathrm{t}$ \\
\hline \multirow{8}{*}{$\begin{array}{l}\text { Independent } \\
\text { variables }\end{array}$} & Constant & & $-4.758 * * *$ & & $-5.042 * * *$ & & $-4.252 * * *$ & & $-2.900 * * *$ & & $-4.215 * * *$ & & $-5.137 * * *$ \\
\hline & $T 1$ & 0.014 & 1.233 & & & & & & & & & & \\
\hline & $T 2$ & & & 0.023 & $2.053 * *$ & & & & & & & & \\
\hline & $T 3$ & & & & & -0.001 & -0.069 & & & & & & \\
\hline & $T 4$ & & & & & & & -0.037 & $-3.364 * * *$ & & & & \\
\hline & $T 5$ & & & & & & & & & -0.002 & -0.197 & & \\
\hline & NoW & & & & & & & & & & & 0.068 & $3.228 * * *$ \\
\hline & $(\mathrm{NoW})^{2}$ & & & & & & & & & & & -0.035 & $-1.658 * *$ \\
\hline \multirow{11}{*}{$\begin{array}{l}\text { Control } \\
\text { variables }\end{array}$} & Kit & -0.027 & $-2.301 * *$ & -0.028 & $-2.328 * *$ & -0.028 & $-2.322 * *$ & -0.027 & $-2.276^{* *}$ & -0.028 & $-2.318 * *$ & -0.028 & $-2.357 * *$ \\
\hline & Int & 0.041 & $3.288 * * *$ & 0.041 & $3.326 * * *$ & 0.041 & $3.280 * * *$ & 0.040 & $3.249 * * *$ & 0.041 & $3.282 * * *$ & 0.041 & $3.308 * * *$ \\
\hline & Wash & -0.052 & $-4.123 * * *$ & -0.052 & $-4.124 * * *$ & -0.052 & $-4.152 * * *$ & -0.052 & $-4.116 * * *$ & -0.052 & $-4.148 * * *$ & -0.052 & $-4.154 * * *$ \\
\hline & Swim & 0.002 & 0.163 & 0.002 & 0.203 & 0.002 & 0.144 & 0.002 & 0.172 & 0.002 & 0.142 & 0.003 & 0.232 \\
\hline & Air & 0.041 & $3.350 * * *$ & 0.041 & $3.338 * * *$ & 0.041 & $3.359 * * *$ & 0.042 & $3.380 * * *$ & 0.041 & $3.353 * * *$ & 0.040 & $3.248 * * *$ \\
\hline & Park & -0.102 & $-8.853 * * *$ & -0.101 & $-8.803 * * *$ & -0.102 & $-8.808 * * *$ & -0.100 & $-8.722 * * *$ & -0.102 & $-8.815^{* * *}$ & -0.103 & $-8.977 * * *$ \\
\hline & $A c c$ & 0.135 & $11.327 * * *$ & 0.134 & $11.253 * * *$ & 0.135 & $11.293 * * *$ & 0.135 & $11.338 * * *$ & 0.135 & $11.301 * * *$ & 0.135 & $11.316^{* * * *}$ \\
\hline & Bed & 0.033 & $3.001 * * *$ & 0.034 & $3.021 * * *$ & 0.033 & $3.003 * * *$ & 0.033 & $3.005 * * *$ & 0.033 & $3.005 * * *$ & 0.034 & $3.052 * * *$ \\
\hline & City & 0.125 & $9.687 * * *$ & 0.124 & $9.597 * * *$ & 0.124 & $9.629 * * *$ & 0.123 & $9.532 * * *$ & 0.124 & $9.606 * * *$ & 0.124 & $9.602 * * *$ \\
\hline & SH & 0.317 & $28.137 * * *$ & 0.317 & $28.087 * * *$ & 0.317 & $28.121 * * *$ & 0.317 & $28.112 * * *$ & 0.317 & $28.122 * * *$ & 0.314 & $27.791 * * *$ \\
\hline & RLen & -0.039 & $-3.475 * * *$ & -0.039 & $-3.443 * * *$ & -0.039 & $-3.482 * * *$ & -0.039 & $-3.423 * * *$ & -0.039 & $-3.482 * * *$ & -0.040 & $-3.572 * * *$ \\
\hline
\end{tabular}

$* * p<.05 ; * * * p<.01$. 
Table 4. Additional regression analysis

\begin{tabular}{|c|c|c|c|}
\hline \multirow[b]{2}{*}{ Type } & \multirow[b]{2}{*}{ Variable } & \multicolumn{2}{|c|}{ Model } \\
\hline & & $\begin{array}{l}\text { Std. } \\
\text { coef. }\end{array}$ & $\mathrm{t}$ \\
\hline \multirow{7}{*}{$\begin{array}{l}\text { Independent } \\
\text { variables }\end{array}$} & Constant & & -1.157 \\
\hline & $T 2$ & 0.031 & $2,056^{* *}$ \\
\hline & $T 3$ & 0.013 & 0,884 \\
\hline & $T 4$ & -0.035 & $-2,479 * *$ \\
\hline & $T 5$ & 0.015 & 1,076 \\
\hline & NoW & 0.119 & $5,088 * * *$ \\
\hline & $(\mathrm{NoW})^{2}$ & -0.069 & $-3,001 * * *$ \\
\hline \multirow{9}{*}{$\begin{array}{l}\text { Control } \\
\text { variables }\end{array}$} & Kit & -0.047 & $-3,567 * * *$ \\
\hline & Int & 0.054 & $4,009 * * *$ \\
\hline & Wash & -0.054 & $-3,909 * * *$ \\
\hline & Swim & -0.003 & -0.253 \\
\hline & Air & 0.063 & $4,679 * * *$ \\
\hline & Park & -0.097 & $-7,631 * * *$ \\
\hline & $A c c$ & 0.159 & $12,192 * * *$ \\
\hline & Bed & 0.041 & $3.388^{* * *}$ \\
\hline & City & 0.120 & $8.426^{* * *}$ \\
\hline
\end{tabular}

